\title{
A Critical Role of Ser26 Hydrogen Bonding in A $\beta 42$ Assembly and Toxicity
}

\author{
Robin Roychaudhuri, ${ }^{\dagger, \S}$ Tien-Phat V. Huynh, ${ }^{\dagger, \|}$ Taylor R. Whitaker, ${ }^{\dagger}$ Elisabeth Hodara, ${ }^{\dagger}$ \\ Margaret M. Condron, ${ }^{\dagger}$ and David B. Teplow*, ${ }^{\dagger,+0}$ \\ ${ }^{\dagger}$ Department of Neurology, David Geffen School of Medicine at UCLA, Los Angeles, California 90095, United States \\ ${ }^{*}$ Molecular Biology Institute and Brain Research Institute, University of California, Los Angeles, California 90095, United States
}

Supporting Information

\begin{abstract}
Amyloid $\beta$-protein $(\mathrm{A} \beta$ ) assembly is a seminal process in Alzheimer's disease. Elucidating the mechanistic features of this process is thought to be vital for the design and targeting of therapeutic agents. Computational studies of the most pathologic form of $\mathrm{A} \beta$, the 42-residue $\mathrm{A} \beta 42$ peptide, have suggested that hydrogen bonding involving Ser26 may be particularly important in organizing a monomer folding nucleus and in subsequent peptide assembly. To study this question, we experimentally determined structure-activity relationships among A $\beta 42$ peptides in which Ser26 was replaced with Gly, Ala, $\alpha$-aminobutryic acid (Abu), or Cys. We observed that aliphatic substitutions (Ala and $\mathrm{Abu}$ ) produced substantially increased rates of formation of $\beta$-sheet, hydrophobic surface, and fibrils, and higher levels of cellular toxicity. Replacement of the Ser hydroxyl group with a sulfhydryl moiety (Cys) did not have these effects. Instead, this peptide behaved like native $\mathrm{A} \beta 42$, even though the hydropathy of Cys was similar to that of $\mathrm{Abu}$ and very different from that of Ser. We conclude that $\mathrm{H}$ bonding of Ser26 is the factor most important in its contribution to $\mathrm{A} \beta 42$ conformation, assembly, and subsequent toxicity.
\end{abstract}

\footnotetext{
A lzheimer's disease $(\mathrm{AD})$ is a fatal neurodegenerative disease and the sixth leading cause of death in the United States. $^{2}$ Of all the factors implicated in the etiology of this multifactorial disease, pathologic assembly of the 42-residue form of the amyloid $\beta$-protein $(\mathrm{A} \beta), \mathrm{A} \beta 42,{ }^{3,4}$ correlates most strongly. Assembly includes formation of both fibrils and oligomers, the latter of which may be the most important $\mathrm{AD}$ neurotoxins. ${ }^{5}$ Prior studies have sought to elucidate the conformational dynamics of $\mathrm{A} \beta 42$ monomer folding and oligomer formation. ${ }^{6,7}$ These studies revealed that the $\mathrm{A} \beta$ monomer contains a 10-residue segment, $\mathrm{Ala}^{21}$-Glu-Asp-ValGly-Ser-Asn-Lys-Gly-Ala ${ }^{30}$, that forms a protease resistant turn structure nucleating monomer folding. Structural changes within this nucleus that cause familial $\mathrm{AD}$ (FAD) or cerebral amyloid angiopathy have been shown to destabilize its turn, resulting in facilitation of $\mathrm{A} \beta$ assembly. ${ }^{8,9}$ These observations supported the idea that the decapeptide region of $\mathrm{A} \beta$ could be a therapeutic target. A number of studies have focused specifically on Ser26. Computational studies have suggested that Ser26 is involved in an extensive $\mathrm{H}$ bonding network stabilizing the turn
}

structure. ${ }^{10}$ Experimental studies of $\mathrm{N}_{\alpha}$-acetyl-Ser26-O-acyliso$\mathrm{A} \beta 42$, an isomer of $\mathrm{A} \beta 42$ in which Ser26 is connected to Gly25 through an ester bond to its $\beta$-hydroxyl group, showed striking effects on peptide assembly. ${ }^{11}$ One explanation for this finding was that the ester bond disrupted the normal $\mathrm{H}$ bonding ability of the Ser hydroxyl group. To explore more fully how Ser26 impacts monomer folding and assembly, we synthesized peptides in which Ser was replaced with Gly, Ala, $\alpha$ aminobutryic acid (Abu), or Cys (Figure 1). These substitutions eliminate $\mathrm{H}$ bonding ability (Gly, Ala, and Abu) and produce a range of amino acid hydropathy of from -0.8 to 2.5.

We first used photochemical cross-linking, sodium dodecyl sulfate-polyacrylamide gel electrophoresis, and silver staining (Figure 2) to determine the oligomerization states of aggregatefree peptide populations immediately after solubilization at 22.5 ${ }^{\circ} \mathrm{C}$ in $20 \mathrm{mM}$ sodium phosphate $(\mathrm{pH} 7.5)$ at a nominal concentration of $0.5 \mathrm{mg} / \mathrm{mL}$ (see experimental details in the Supporting Information). ${ }^{12}$

The A $\beta 42$ ("Ser" ${ }^{a}$ ) distribution comprised monomer through octamer, with an intensity node at pentamer/hexamer, consistent with prior studies. ${ }^{12,13}$ Qualitatively similar distributions were observed for the four substituted peptides, with the exception of the absence of octamer bands. To enable quantitative comparisons of band intensities to be made, we normalized the data within each lane (Table S1).

$\mathrm{Ala}, \mathrm{Abu}$, and $\mathrm{Gly}^{b}$ displayed significant increases in levels of dimer $(p<0.01)$, trimer $(p<0.05$ or $p<0.01)$, tetramer $(p<$ $0.01)$, and pentamer $(p<0.05$ or $p<0.01)$. No significant differences in hexamer intensities were observed. All four substituted peptides had lower levels of heptamer. The heptamer levels for Ala and Abu were significantly lower $(p<$ 0.01). No peptide, except Ser, formed octamers. One explanation for the greater propensity of Ser, relative to those of the other peptides, to form heptamers and octamers may be its enhanced ability to stabilize the intrinsically disordered $\mathrm{A} \beta$ monomer in a conformational state that provides greater stability to the higher-order oligomers.

We next monitored $\beta$-sheet formation using thioflavin $\mathrm{T}$ (ThT) binding (Figure 3) (see experimental details in the Supporting Information). ${ }^{14-16}$ Initial rates of increase in

Received: August 10, 2017

Revised: November 8, 2017

Published: November 15, 2017 
<smiles>CN[C@@H](CO)C(C)=O</smiles>

Ser

$$
2.5
$$<smiles>CN[C@H](CS)C(C)=O</smiles>

Cys
1.8-2.5<smiles>CC[C@H](NC)C(C)=O</smiles>

Abu
1.8<smiles>CN[C@@H](C)C(C)=O</smiles>

Ala
$-0.4$<smiles>CCC(C)=O</smiles>

Gly

Figure 1. Structures of amino acids at position 26 of A $\beta 42$. Numbers above side chains are Kyte-Doolittle hydropathy indices. ${ }^{1}$ The Abu index was not specified but should be between those of Ala (1.8) and Val (2.5).

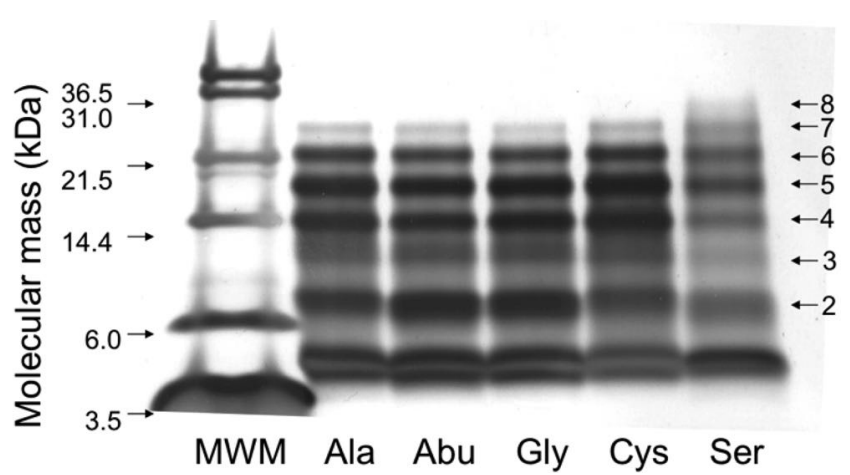

Figure 2. Oligomer size distributions. Peptide substitutions are indicated. Lane MWM contained molecular weight markers. Numbers at the right specify oligomer size (numbers of $\mathrm{A} \beta$ monomers/ oligomer).

fluorescence displayed the following rank order: Ala $\gg \mathrm{Abu} /$ Gly $\gg$ Ser/Cys (Figure 3A). Lag times correlated inversely with the initial rates of increase in ThT. These data suggest that the presence of a small apolar side chain (methyl or ethyl) facilitates initial peptide assembly relative to the more polar side chains of Ser and Cys. This may be due to enhanced hydrophobic interactions leading to monomer self-association. Final fluorescence levels were highest for $\mathrm{Ala}$ and $\mathrm{Abu}$, followed by Ser/Gly, and then Cys (Figure 3B). Gly may behave like Ser with respect to its effect on the end-stage assembly state because its loss of $\mathrm{H}$ bonding capability may be balanced by its strong entropic contribution to folding and assembly. Cys assembled the slowest and produced very low maximum fluorescence. Cys, Abu, and Ala all have relatively high hydropathy indices $(2.5,1.8-2.5$, and 1.8 , respectively), and Cys and Abu have side chains that are similar in size. The distinct behavior of Cys thus must be due to distinct effects engendered by its sulfhydryl group compared to the methyl group of $\mathrm{Abu}$ and the lack of a $\mathrm{C}_{\beta}$ substitution in Ala.

Time-dependent changes in secondary structure were monitored by circular dichroism (CD) spectroscopy (Figure S1A-E) (see experimental details in the Supporting Information). ${ }^{17,18}$ All peptides displayed initial spectra consistent with a statistical coil. This was followed by an apparent two-state coil $\rightarrow \beta$-sheet transition (isosbestic points between 206 and $210 \mathrm{~nm}$ ). To compare the kinetics of $\beta$-sheet formation among the peptides, we plotted the time dependence of the molar ellipticity at $215 \mathrm{~nm}\left[[\theta]_{215}\right.$ (Figure S1F)]. All peptides, except Cys, reached their maximal $\beta$-sheet content between 2 and $4 \mathrm{~h}$. Cys had maximal $\beta$-sheet structure by $\approx 8 \mathrm{~h}$. The $[\theta]_{215}$ values decreased in the following order: Ala/Abu/ Gly $\geq$ Ser $>$ Cys. This pattern was consistent with the rank order of lag times observed in the ThT experiments.

We also monitored peptide assembly using SYPRO fluorescence (see experimental details in the Supporting Information), which occurs when the dye binds to exposed hydrophobic surfaces of proteins. ${ }^{19,20}$ Initial kinetics (Figure S2A) showed that both $\mathrm{Ala}$ and $\mathrm{Abu}$ had similar rates of assembly for $\leq 3 \mathrm{~h}$, after which Abu rates slowed modestly. Gly assembled initially as rapidly as Ala and Abu, but assembly plateaued at a low fluorescence intensity after $\approx 3 \mathrm{~h}$. Ser and Cys assembled slower, but unlike Gly, they progressively displayed higher fluorescence intensities (Figure S2B). This
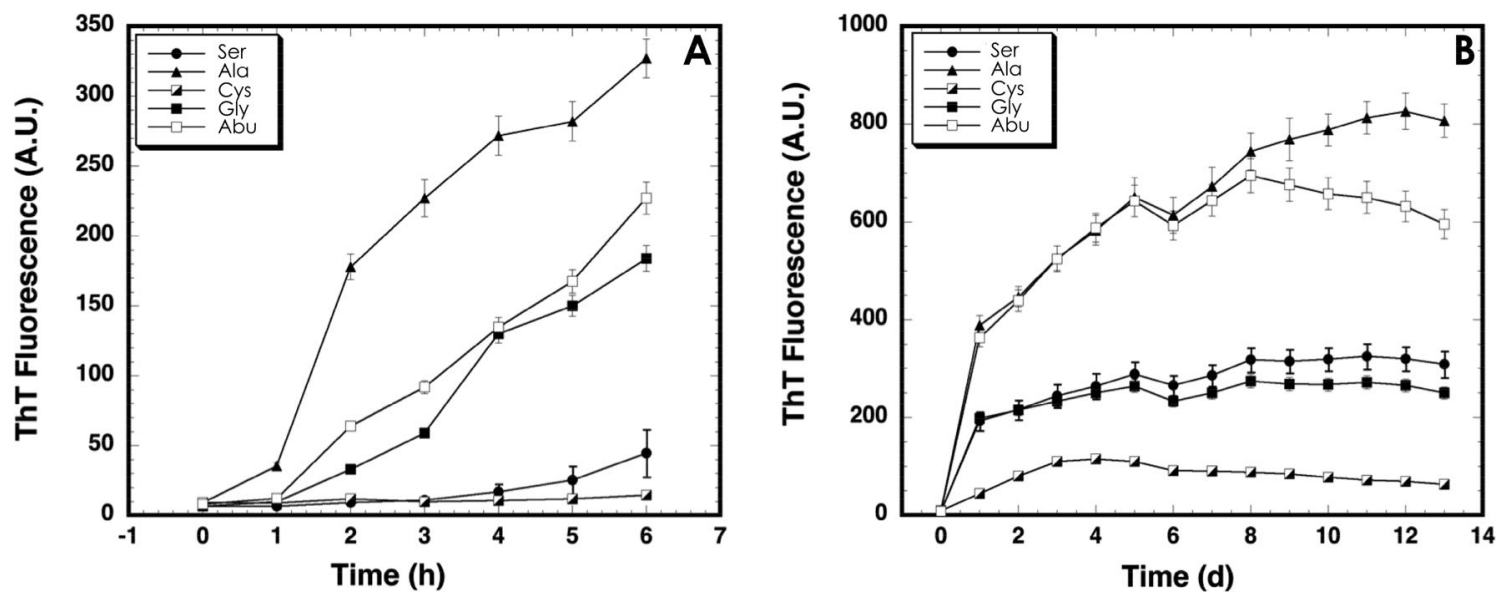

Figure 3. Kinetics of $\beta$-sheet formation monitored by ThT fluorescence. Panels are: (A) kinetics during the first $6 \mathrm{~h}$ of incubation; and (B) overall kinetics. Error bars are the standard deviations. 

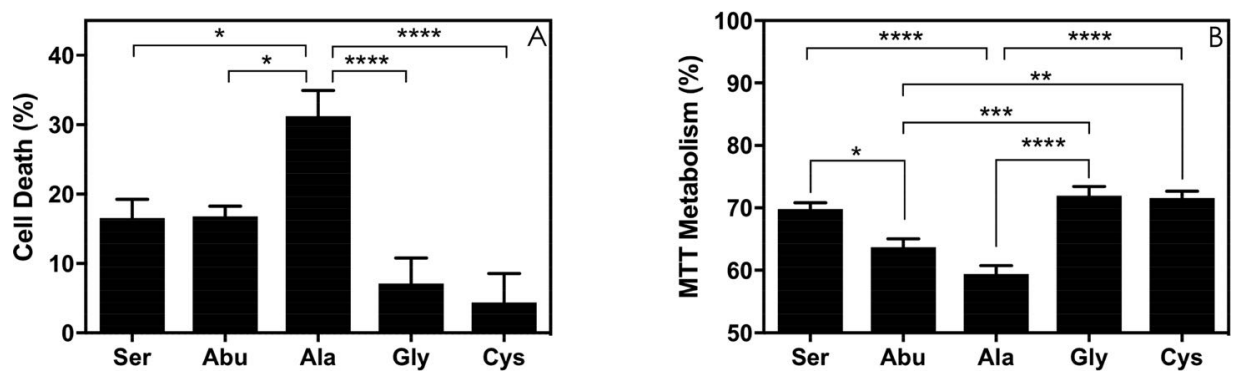

Figure 4. Neurotoxicity assays. Panels are: (A) LDH assays; and (B) MTT assays. MTT metabolism is determined relative to buffer control. Error bars are the standard deviations. Statistical significance of differences among samples is indicated as follows: $*_{p}<0.05 ; * * \leq 0.01 ; * * p<0.001$; and $* * * * p<0.0001$.

rank order suggests that the apolar side chains of Ala and Abu are most able, relative to the other peptides, to contribute to the formation of hydrophobic surfaces. Gly also rapidly produced hydrophobic surfaces, possibly because of the conformational freedom it afforded the peptide backbone and not because of any direct hydrophobic effects. Maximum fluorescence intensities were observed by $24 \mathrm{~h}$ and displayed the following rank order: Ala/Ser $\geq \mathrm{Abu} / \mathrm{Cys} \gg$ Gly. We ascribe the modest maximum fluorescence of Gly to its lack of a residue 26 side chain, which has little effect on the initial phases of fluorescence increases, during which initial monomer selfassociation occurs, but cannot contribute directly to the formation of hydrophobic surfaces.

To establish structure-toxicity relationships, we performed cell death (LDH) and cell metabolism (MTT) assays by incubating freshly prepared peptides and NGF-differentiated PC12 cells together for $16 \mathrm{~h}$ (see experimental details in the Supporting Information). Ala was most toxic in the LDH assay (Figure 4A). Ser and Abu were less but equally toxic, whereas Gly and Cys were minimally toxic. In the MTT assay, all peptides displayed substantial toxicity, with a rank order of Ala $>\mathrm{Abu}>\mathrm{Ser} / \mathrm{Gly} / \mathrm{Cys}$ (Figure 4B). This order was consistent with that found in the $\mathrm{LDH}$ assay, with the exception that Ser was not as toxic as Abu. The order also was consistent with the rank order of fluorescence observed in the ThT experiments, which shows that the formation of $\beta$-sheets during the first $16 \mathrm{~h}$ of incubation and toxicity are correlated. This period reflects predominately initial peptide oligomerization and early fibril formation (see electron microscopy results below).

To determine the morphologies of assemblies, we performed electron microscopy (see experimental details in the Supporting Information). On day 0, Ser displayed a few small globules (Figure S3A, white circle) and $\operatorname{short}^{c}$ fibrils that appeared twisted (white arrows). Abu also displayed some globules (white circles), but the majority of structures were thin (black arrows) and thick (white arrows) fibrils, fibrils with helical twisting (green arrow), and what appeared to be linear associations of globules (red arrow). Ala had formed numerous thin fibrils (black arrows) that often were fasciculated (red arrows), as well as some globules (white circles). Gly and Cys both produced abundant aggregates composed of irregular globular structures, but no long fibrils. Short elongated structures with relatively constant diameters were seen occasionally within the aggregates formed by Gly (black arrows). Dimensions of the assemblies are listed in Table S2.

After being incubated for 14 days, all peptides had formed abundant fibrils (Figure S3B). Ser formed relatively straight short and long fibrils that appeared to be composed of one (black arrows) or two (green arrows) individual filaments. Both straight (red arrow) and twisted (blue arrows) morphologies were seen. Abu produced a network of long fibrils of relatively constant diameter. Single filaments (black arrows) and, more often, bifilar structures (white arrows) were formed by Ala. Gly produced abundant thin filaments with occasional twisted substructures (black and white arrows). Thin filaments also predominated in the Cys sample.

The absence of rapid fibril formation by Gly and Cys (day 0) correlates with the observation that these peptides were the least toxic in MTT and LDH assays. Ser, which displayed very few fibril-like structures, had equally modest toxicity in MTT assays but was more toxic than Gly or Cys in $\mathrm{LDH}$ assays. These data are consistent with the interpretation of the toxicity data that suggested that during a $16 \mathrm{~h}$ assay, those peptides that can assemble most rapidly are the most toxic.

In summary, aliphatic substitutions (Ala and $\mathrm{Abu}$ ) at position 26 produced substantially increased rates of formation of $\beta$ sheet, hydrophobic surface, and fibrils, and higher levels of toxicity in MTT assays. Sulfhydryl substitution (Cys), which produces a side chain as apolar as $\mathrm{Abu}$, did not have these effects. Instead, Cys behaved more like Ser with respect to initial rates of formation of $\beta$-sheet and hydrophobic surface and with respect to MTT assay activity. These similarities were observed in spite of the fact that their hydropathy indices showed the greatest difference $(2.5$ vs -0.8$)$ among all peptides. Interestingly, Gly and Cys, which also exhibit large differences in side-chain size and hydropathy ( -0.4 vs 2.5 ), had similar effects on toxicity and fibril formation. We note that Cys did differ from Ser in overall fibril assembly rate. Increasing the hydrophobicity of the side chain at position 26 leads to the formation of fibrils at day 0 of the assembly process. However, Cys, which is the most hydrophobic of the substituted amino acids, forms fibrils unlike those formed by Abu or Ala, which also have apolar side chains. This suggests that, in addition to hydrophobic interactions, other factors such as $\mathrm{H}$ bonding or Coulombic interactions play roles in the initial stages of assembly. Upon comparison of the structures of Ser, Cys, and $\mathrm{Abu}$ (Figure 1), it is clear that the distinct behaviors of these peptides cannot be ascribed simply to their side-chain sizes or geometries, which are similar, or to their hydropathy indices, which vary substantially between peptides exhibiting similar behaviors. Instead, the structural feature that appears to distinguish Ser and Cys from $\mathrm{Abu}$ is their ability to $\mathrm{H}$ bond. We conclude that $\mathrm{H}$ bonding of Ser26 may be the factor most important in its contribution to A $\beta 42$ conformation, assembly, and subsequent toxicity. In addition, our results reveal an important caveat with respect to therapeutic strategies targeting Ser26, namely that targeting the hydroxymethyl side chain must 
not result in facilitation of assembly and toxicity, as observed with Ala and Abu.

\section{ASSOCIATED CONTENT}

\section{S Supporting Information}

The Supporting Information is available free of charge on the ACS Publications website at DOI: 10.1021/acs.biochem.7b00772.

Experimental details, supporting tables, and supporting figures (PDF)

\section{AUTHOR INFORMATION}

\section{Corresponding Author}

*E-mail: dteplow@mednet.ucla.edu.

ORCID $\odot$

David B. Teplow: 0000-0002-2389-3417

\section{Present Addresses}

${ }^{\S}$ R.R.: The Solomon H. Snyder Department of Neuroscience, Johns Hopkins University School of Medicine, 725 N. Wolfe St., Baltimore, MD 21205.

"T.-P.V.H.: Hope Center for Neurological Disorders, Department of Neurology, Washington University School of Medicine, 660 S. Euclid Ave., St. Louis, MO 63110.

\section{Author Contributions}

R.R. and D.B.T. designed the experiments. M.M.C. synthesized the peptides. R.R., T.-P.V.H., T.R.W., and E.H. performed the experiments. R.R., T.-P.V.H., T.R.W., E.H., and D.B.T. analyzed the data. All authors contributed to the writing of the manuscript.

\section{Funding}

National Institutes of Health Grants AG042195 and NS038328 to D.B.T.

Notes

The authors declare no competing financial interest.

\section{ACKNOWLEDGMENTS}

We thank members of the Teplow laboratory for critical comments.

\section{ADDITIONAL NOTES}

${ }^{a}$ For the sake of simplicity, we refer to each of the substituted A $\beta 42$ peptides using only the name of the substituted amino acid.

${ }^{b}$ Although the dimer intensity of Gly trended higher than that of Ser, the Gly dimer intensity variance was too large to make the difference significant.

"We refer to "short" and "long" fibrils only to distinguish those fibrils with lengths in the nanometer range that are entirely visible within an image (short) from those whose lengths are in the micrometer length regime and whose ends are not visible (long). Long fibrils are $>1 \mu \mathrm{m}$ in length.

\section{REFERENCES}

(1) Kyte, J., and Doolittle, R. F. (1982) J. Mol. Biol. 157, 105-132.

(2) 2017 Alzheimer's disease facts and figures (2017) Alzheimer's Association, Chicago.

(3) Roychaudhuri, R., Yang, M., Hoshi, M. M., and Teplow, D. B. (2009) J. Biol. Chem. 284, 4749-4753.

(4) Hayden, E. Y., and Teplow, D. B. (2013) Alzheimer's Res. Ther. 5,
(5) Dahlgren, K. N., Manelli, A. M., Stine, W. B., Jr., Baker, L. K., Krafft, G. A., and LaDu, M. J. (2002) J. Biol. Chem. 277, 32046-32053.

(6) Lazo, N. D., Grant, M. A., Condron, M. C., Rigby, A. C., and Teplow, D. B. (2005) Protein Sci. 14, 1581-1596.

(7) Borreguero, J. M., Urbanc, B., Lazo, N. D., Buldyrev, S. V., Teplow, D. B., and Stanley, H. E. (2005) Proc. Natl. Acad. Sci. U. S. A. $102,6015-6020$.

(8) Krone, M. G., Baumketner, A., Bernstein, S. L., Wyttenbach, T., Lazo, N. D., Teplow, D. B., Bowers, M. T., and Shea, J. E. (2008) J. Mol. Biol. 381, 221-228.

(9) Grant, M. A., Lazo, N. D., Lomakin, A., Condron, M. M., Arai, H., Yamin, G., Rigby, A. C., and Teplow, D. B. (2007) Proc. Natl. Acad. Sci. U. S. A. $104,16522-16527$.

(10) Baumketner, A., Bernstein, S. L., Wyttenbach, T., Lazo, N. D., Teplow, D. B., Bowers, M. T., and Shea, J. E. (2006) Protein Sci. 15, 1239-1247.

(11) Roychaudhuri, R., Lomakin, A., Bernstein, S., Zheng, X., Condron, M. M., Benedek, G. B., Bowers, M., and Teplow, D. B. (2014) J. Mol. Biol. 426, 2422-2441.

(12) Bitan, G., Lomakin, A., and Teplow, D. B. (2001) J. Biol. Chem. 276, 35176-35184.

(13) Bitan, G., and Teplow, D. B. (2004) Acc. Chem. Res. 37, 357364.

(14) Naiki, H., and Nakakuki, K. (1996) Lab. Invest. 74, 374-383.

(15) LeVine, H., 3rd. (1999) Methods Enzymol. 309, 274-284.

(16) Groenning, M. (2010) J. Chem. Biol. 3, 1-18.

(17) Roychaudhuri, R., Zheng, X., Lomakin, A., Maiti, P., Condron, M. M., Benedek, G. B., Bitan, G., Bowers, M. T., and Teplow, D. B. (2015) ACS Chem. Neurosci. 6, 1941-1955.

(18) Siligardi, G., and Hussain, R. (2015) Methods Mol. Biol. 1261, 255-276.

(19) Wong, A. G., and Raleigh, D. P. (2016) Protein Sci. 25, 18341840.

(20) He, F., Phan, D. H., Hogan, S., Bailey, R., Becker, G. W., Narhi, L. O., and Razinkov, V. I. (2010) J. Pharm. Sci. 99, 2598-2608. 60. 


\section{Supporting Information}

\section{A critical role of Ser26 hydrogen bonding in $A \beta 42$ assembly and toxicity}

Robin Roychaudhuri ${ }^{\ddagger \perp}$, Tien-Phat V. Huynh ${ }^{\ddagger}$, Taylor R. Whitaker ${ }^{\ddagger}$, Elisabeth Hodara ${ }^{\ddagger}$, Margaret M. Condron ${ }^{\ddagger}$, and David B. Teplow ${ }^{\dagger *}$

'Department of Neurology, David Geffen School of Medicine at UCLA, Los Angeles, CA;

${ }^{\dagger}$ Molecular Biology Institute and Brain Research Institute, University of California, Los Angeles, California 9009

\section{The supporting information contains Experimental Details, Figures S1-S3, and Tables S1 and S2}

Present addresses:

$\perp$ The Solomon H. Snyder Dept. of Neuroscience, Johns Hopkins University School of Medicine, 725 N Wolfe Street, Baltimore, MD21205

${ }^{\diamond}$ Hope Center for Neurological Disorders, Department of Neurology, Washington University School of Medicine, 660 S. Euclid Avenue, St. Louis, Missouri 63110 USA 


\section{Supporting Information}

\section{EXPERIMENTAL DETAILS}

Chemicals and Reagents. All chemicals were purchased from Sigma Chemical Co. (Saint Louis, MO) and were of the highest purity available. Water was de-ionized and filtered using a Milli-Q system (Millipore Corp., Bedford, MA). YM-50 kDa filters were purchased from Millipore Corp. Xpress ${ }^{\mathrm{TM}}$ silver-staining kit was from Invitrogen (Carlsbad, CA).

Peptide Synthesis. All peptides were synthesized using 9-fluorenylmethoxycarbonyl (Fmoc) chemistry and purified by reverse phase high performance liquid chromatography (RP-HPLC), essentially as described. ${ }^{1}$ The identity and purity (usually $>97 \%$ ) of the peptides were confirmed by amino acid analysis, mass spectrometry, and reverse phase high performance liquid chromatography (RP-HPLC).

Preparation of low molecular weight (LMW) A 342 . LMW A $\beta$, an equilibrium mixture of monomers and dimers, ${ }^{2}$ was prepared by dissolving peptide lyophilizates in a solution comprising 10\% (v/v) $60 \mathrm{mM} \mathrm{NaOH:} \mathrm{45 \% (v/v)} \mathrm{milliQ} \mathrm{water:} \mathrm{45 \%} \mathrm{(v/v)} 20 \mathrm{mM}$ sodium phosphate, $\mathrm{pH}$ 7.5. The nominal concentration was $0.5-1 \mathrm{mg} / \mathrm{ml}$. The solutions were sonicated for $1 \mathrm{~min}$ in a Branson 1200 bath sonicator (Branson Ultrasonics Corp, Danbury CT). The peptide solutions were then centrifuged in a pre-wetted YM-50 kDa filter at $16,000 \times \mathrm{g}$ for 10 min. After centrifugation and filtering, the concentration of the peptides was determined spectrophotometrically using $\varepsilon_{280}=1315 \mathrm{~cm}^{-1} \mathrm{M}^{-1}$. Peptides were maintained on ice until use.

Photo-Induced Crosslinking of Unmodified Proteins (PICUP). A $\beta$ oligomerization was monitored using PICUP, essentially as described. ${ }^{3}$ The peptides were prepared at a nominal 


\section{Supporting Information}

concentration of $0.5-1 \mathrm{mg} / \mathrm{ml}$ as described in "Preparation of $L M W A \beta 42$ ". The peptides then were incubated at RT. Eighteen $\mu 1$ of sample were periodically subjected to the PICUP reaction. ${ }^{4}$ Briefly, $1 \mu \mathrm{l}$ of $2 \mathrm{mM}$ Tris (2,2'-bipyridyl) dichlororuthenium (II) hexahydrate (Ru(bpy)) was added to a $0.2 \mathrm{ml}$ thin-walled PCR tube (Eppendorf AG, Hamburg, Germany) containing the sample, followed by addition of $1 \mu 1$ of $40 \mathrm{mM}$ ammonium persulfate (APS) in PBS, $\mathrm{pH}$ 7.5. The tube then was irradiated for $1 \mathrm{~s}$ with incandescent light using a high intensity illuminator (DolanJenner Industries Inc., Model 170-D). The reaction was quenched immediately with $1 \mu 11 \mathrm{M}$ DTT in water and the sample was vortexed and placed on ice. To determine the oligomer size distribution, an equal volume of $2 \times$ Tris-Tricine SDS sample buffer (Invitrogen, Carlsbad, CA) was added to each sample. The samples then were boiled in a $100^{\circ} \mathrm{C}$ water bath for $10 \mathrm{~min}$ and electrophoresed on a 10-20\% T, $1 \mathrm{~mm}$ thick, Tris-Tricine SDS gel (Invitrogen, Carlsbad, CA). The gel was silver stained using the X-press ${ }^{\mathrm{TM}}$ silver staining kit.

Thioflavin $T$ (ThT) Fluorescence. A $\beta 42$ peptide solutions were prepared as mentioned in “Preparation of $L M W A \beta 42$ ". Approximately 60-80 $\mu 1$ of each peptide, at a concentration of 20 $\mu \mathrm{M}$ in $20 \mathrm{mM}$ sodium phosphate, $\mathrm{pH} 7.5$, were added to each well of a 96-well optical bottom microtiter plate (Thermo Fisher Scientific, Rochester NY) to give a final peptide concentration of $20 \mu \mathrm{M}$. $1.6 \mu \mathrm{l}$ of ThT at a concentration of $5 \mathrm{mM}$ was added to each well. The volume in each well was adjusted to $200 \mu \mathrm{l}$ by adding phosphate buffer, yielding a final ThT concentration of 40 $\mu \mathrm{M}$. The wells were gently mixed by pipetting, sealed using an adhesive plate sealer, and incubated at $37^{\circ} \mathrm{C}$ with gentle shaking. The plate was read in a microplate reader $\left(\lambda_{\mathrm{ex}}=450 \mathrm{~nm}\right.$, $\lambda_{\mathrm{em}}=482 \mathrm{~nm}$ ) immediately and at regular intervals thereafter. Blank wells contained only ThT and buffer. Five or more replicates were done for each sample. The mean of the blank readings 


\section{Supporting Information}

was subtracted from the mean of the sample readings at each time point and the corrected values, along with SD and mean, were plotted using KaleidaGraph (v4.1, Synergy Software, Reading, PA).

SYPRO Aggregation Assay. Aggregation assays were performed by dissolving peptide lyophilizates in 10\% (v/v) $60 \mathrm{mM} \mathrm{NaOH}, 45 \%$ (v/v) Milli Q water followed by $45 \%(\mathrm{v} / \mathrm{v}) 20$ $\mathrm{mM}$ sodium phosphate, $\mathrm{pH} 7.5$, containing $0.0002 \%$ sodium azide. The solutions were sonicated for 1 minute and placed on ice. Peptide concentrations were determined spectrophotometrically $\left(\varepsilon_{280}=1315 \mathrm{~cm}^{-1} \mathrm{M}^{-1}\right)$. The assays were performed in a 96 well plate and the stock peptide solution was diluted to a final concentration of $20 \mu \mathrm{M}$ in each well in a total volume of $200 \mu \mathrm{l}$. SYPRO dye was diluted in each well from a $100 \times$ stock concentration to $1 \times$ final concentration. The remaining volume in the well was made up with phosphate buffer. The samples were mixed with a pipette and then read immediately thereafter $(\mathrm{t}=0 \mathrm{~min})$ in a 96 well microplate reader at $\left(\lambda_{\mathrm{ex}}=495 \mathrm{~nm}, \lambda_{\mathrm{em}}=580 \mathrm{~nm}\right)$. Readings then were taken at $2 \mathrm{~h}$ intervals for the first ten hours and subsequently at $24 \mathrm{~h}$ intervals until no substantial changes in fluorescence were observed. The data were plotted using Kaleidagraph (v4.1, Synergy Software, Reading, PA).

Circular Dichroism (CD) Spectroscopy. Peptide solutions were prepared as in "Preparation of $L M W A \beta 42$ ". CD spectra were obtained every $30 \mathrm{~min}$ for the first $3 \mathrm{~h}$, and subsequently every hour, using a JASCO J-810 spectropolarimeter (Tokyo, Japan). The CD parameters were: wavelength scan range 190-260 nm, data pitch $0.2 \mathrm{~nm}$, continuous scan mode, scan speed 100 $\mathrm{nm} / \mathrm{min}, 1 \mathrm{sec}$ response, band width $2 \mathrm{~nm}$, and an accumulation of 10 scans per sample per time point. The spectra were smoothed using the means movement smoothing parameter within the 


\section{Supporting Information}

data acquisition software (Spectra Manager). The data were plotted using KaleidaGraph (v 4.1.3).

Electron Microscopy (EM). Formvar 400 mesh grids were glow discharged on a Med010 minideposition system EM glow discharge attachment (model BU007284-T, Balzers Union Ltd, Hudson, NH) containing a cylindrical discharge compartment and an adjacent discharge control and timer unit. Samples were mixed thoroughly and then $8 \mu \mathrm{l}$ was layered carefully onto the grid. The grid was covered and incubated for $20 \mathrm{~min}$ at RT. Liquid was wicked off carefully using a filter paper wick by gently touching the tip of the filter paper to the edge of the grid. Five $\mu 1$ of $2.5 \%(\mathrm{v} / \mathrm{v})$ glutaraldehyde in water were added to the grid, which then was incubated for 3 min in the absence of light. The glutaraldehyde solution was wicked off and replaced with $5 \mu 1$ of $1 \%(\mathrm{w} / \mathrm{v})$ uranyl acetate in water, which then was incubated for 3 minutes in the dark. The grids then were wicked off and air-dried. A JEOL 1200 EX (JEOL Ltd., Tokyo, Japan) transmission electron microscope used to visualize the samples. Image analysis was performed using ImageJ (http://imagej.nih.gov/ij).

MTT (3-(4,5-Dimethylthiazol-2-yl)-2,5-diphenyltetrazolium bromide) Assay: Rat pheochromocytoma (PC12) cells were plated at a density of 30,000 cells per well using 96-well plates. Ninety $\mu 1$ of fresh F-12K medium (ATCC), containing $2.5 \%$ fetal bovine serum and $15 \%$ horse serum, were added to each well. The cells were supplemented with nerve growth factor (NGF; Invitrogen) at a final concentration of $100 \mathrm{ng} / \mathrm{ml}$ to induce neuronal differentiation. PC12 cells were subsequently treated with $20 \mu \mathrm{M}$ freshly prepared $\mathrm{A} \beta 42$ and Ser26-substituted peptides dissolved in differentiation medium (F-12K medium containing $0.5 \% \mathrm{FBS}$ ) for $16 \mathrm{~h}$ at 


\section{Supporting Information}

$37^{\circ} \mathrm{C}$. The effects of the peptides on cell physiology were measured using the MTT cell metabolism assay, as described previously. ${ }^{5,6}$ Briefly, following treatment, $15 \mu$ of MTT was added to each well and incubated for $4 \mathrm{~h}$ at $37^{\circ} \mathrm{C}$. The stop solution was added and incubated overnight at $25^{\circ} \mathrm{C}$. MTT reduction was assessed by measuring absorption at $570 \mathrm{~nm}$ (corrected for background absorbance at $630 \mathrm{~nm}$ ) using a Synergy plate reader (Bio-TEK Instruments, Winooski, VT). Results were normalized to the medium control group (100\%) and expressed as the mean percent MTT metabolism \pm standard deviation (SD). The data was plotted with GraphPad Prism 7. One-way ANOVA and Bonferoni post hoc tests were performed. A minimum of three independent experiments (six wells per data point) was performed.

LDH (Lactate Dehydrogenase) Assay: PC12 cells were plated under similar conditions as described for the MTT assay with growth medium. Following a 24-hour differentiation with NGF (100 ng/ml), the cells were incubated with $20 \mu \mathrm{M}$ A $\beta 42$ and Ser26-substituted isoforms for $16 \mathrm{~h}$ at $37^{\circ} \mathrm{C}$, and cell death was assayed by measuring the release of $\mathrm{LDH}$ as described previously. ${ }^{5,7}$ Data from a minimum of three independent experiments (six wells per data point) were normalized to media control and expressed as mean $\pm \mathrm{SD}$. The data were plotted with GraphPad Prism 7. One-way ANOVA and Bonferoni post hoc tests were performed on the data. 


\section{Supporting Information}

\section{References}

(1) Walsh, D. M., Lomakin, A., Benedek, G. B., Condron, M. M., and Teplow, D. B. (1997) Amyloid $\beta$-protein fibrillogenesis. Detection of a protofibrillar intermediate, J Biol Chem 272, 22364-22372.

(2) Walsh, D. M., Hartley, D. M., Kusumoto, Y., Fezoui, Y., Condron, M. M., Lomakin, A., Benedek, G. B., Selkoe, D. J., and Teplow, D. B. (1999) Amyloid $\beta$-protein fibrillogenesis. Structure and biological activity of protofibrillar intermediates, J Biol Chem 274, 25945-25952.

(3) Bitan, G., and Teplow, D. B. (2004) Rapid photochemical cross-linking--A new tool for studies of metastable, amyloidogenic protein assemblies, Acc Chem Res 37, 357-364.

(4) Bitan, G. (2006) Structural study of metastable amyloidogenic protein oligomers by photo-induced cross-linking of unmodified proteins, Methods Enzymol 413, 217-236.

(5) Fradinger, E. A., Monien, B. H., Urbanc, B., Lomakin, A., Tan, M., Li, H., Spring, S. M., Condron, M. M., Cruz, L., Xie, C. W., Benedek, G. B., and Bitan, G. (2008) C-terminal peptides coassemble into $A \beta 42$ oligomers and protect neurons against $A \beta 42$ induced neurotoxicity, Proc Natl Acad Sci U S A 105, 14175-14180.

(6) Maiti, P., Piacentini, R., Ripoli, C., Grassi, C., and Bitan, G. (2011) Surprising toxicity and assembly behaviour of amyloid $\beta$-protein oxidized to sulfone, Biochem J 433, 323332.

(7) Roychaudhuri, R., Zheng, X., Lomakin, A., Maiti, P., Condron, M. M., Benedek, G. B., Bitan, G., Bowers, M. T., and Teplow, D. B. (2015) Role of species-specific primary structure differences in Aß42 assembly and neurotoxicity, ACS Chem Neurosci 6, 1941-1955. 


\section{Supporting Information}
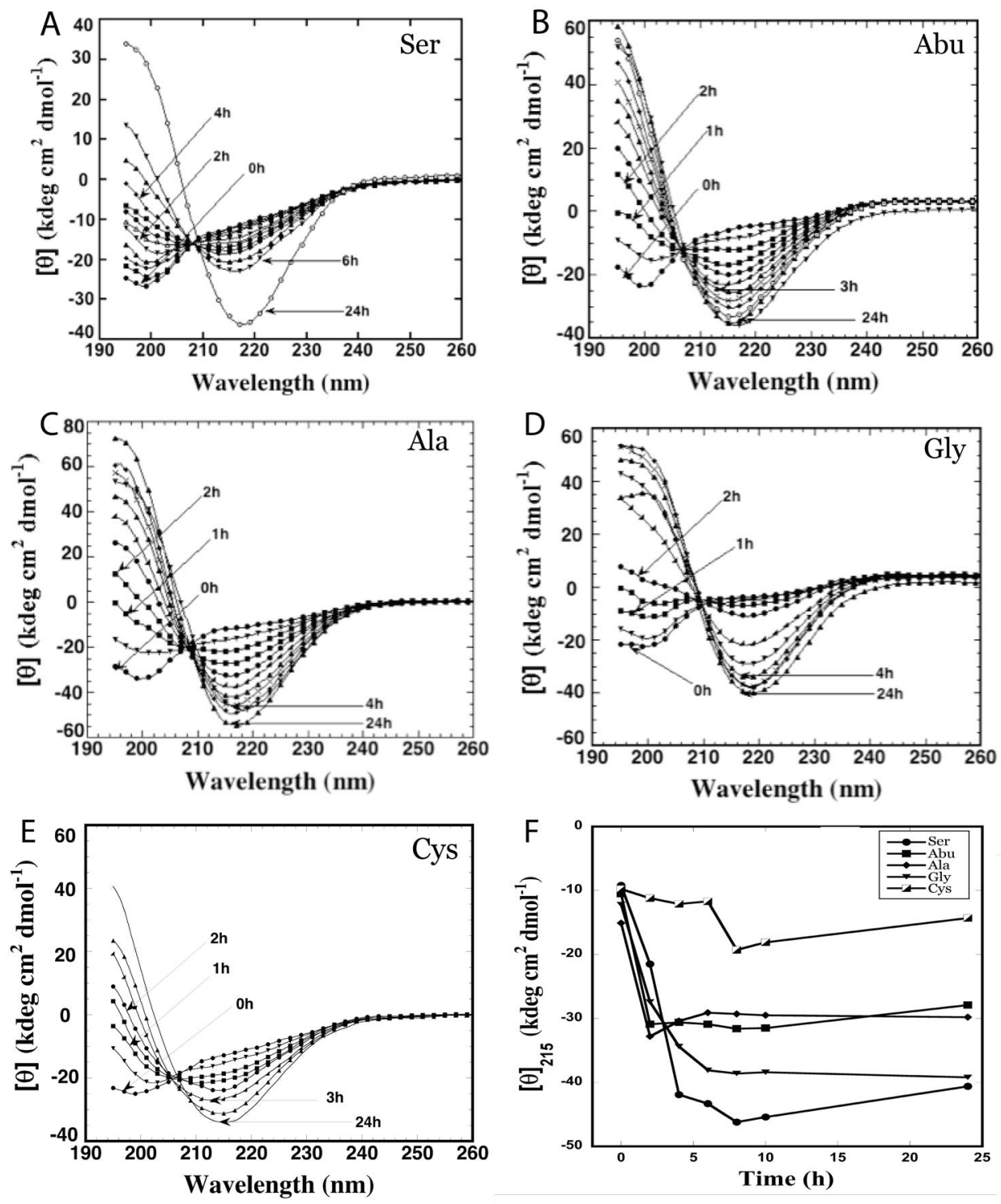

Figure S1. Circular dichroism (CD) spectroscopy. Peptides were dissolved in $20 \mathrm{mM}$ sodium phosphate, $\mathrm{pH} 7.5$, at a final concentration of $20 \mu \mathrm{M}$ and then incubated at $37^{\circ} \mathrm{C}$. Spectra were acquired at regular intervals in a JASCO J-810 CD spectropolarimeter (Tokyo, Japan). Spectra are shown for each of the five peptides: Ser (A), Abu (B), Ala (C), Gly (D), and Cys (E). Mean residue ellipticity $\left([\theta]_{215}\right)$ versus time $(\mathrm{h})$ for the five peptides is plotted in $(\mathbf{F})$. 


\section{Supporting Information}
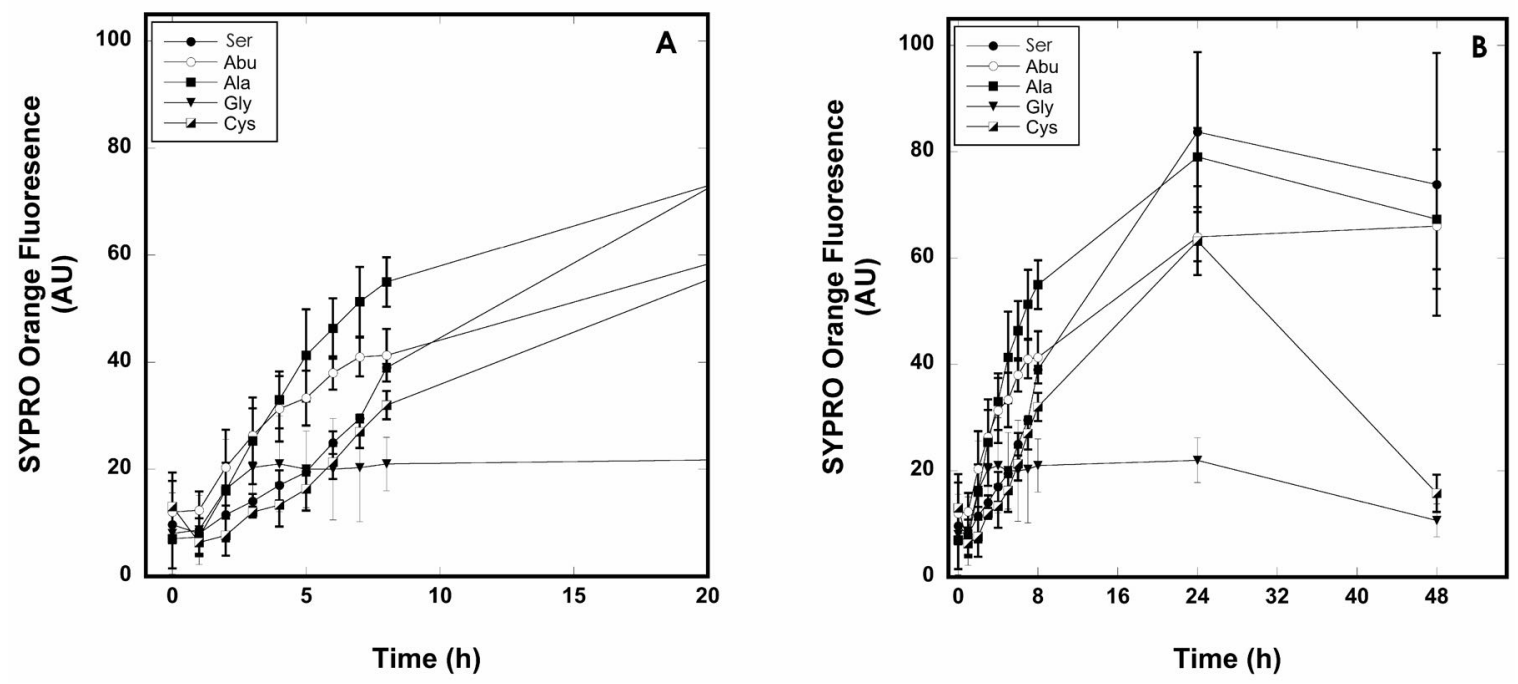

Figure S2. Determining fibril formation kinetics using SYPRO Orange fluorescence. Peptides were dissolved in $20 \mathrm{mM}$ sodium phosphate, $\mathrm{pH} 7.5$, at a final concentration of $20 \mu \mathrm{M}$ and then incubated at $37^{\circ} \mathrm{C}$. Aggregation kinetics was measured using SYPRO Orange dye (200 $\mu \mathrm{M}$ final concentration). (A) Data from the first $8 \mathrm{~h}$ of assembly. (B) Data from entire experiment. Error bars are S.D. 


\section{Supporting Information}
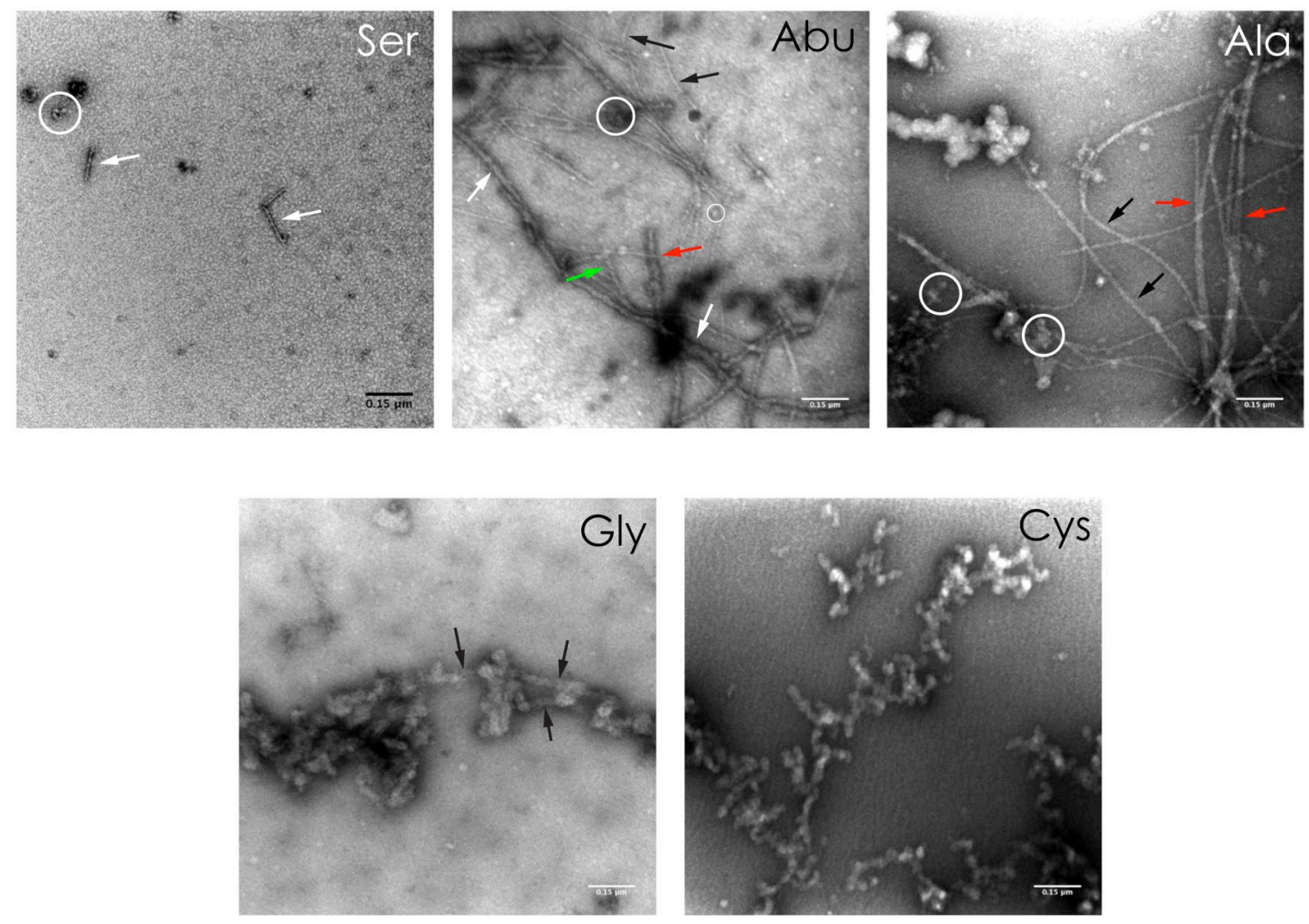

Figure S3A. Electron microscopy of peptide assemblies after initial preparation. Peptides were dissolved in $20 \mathrm{mM}$ sodium phosphate, $\mathrm{pH} 7.5$, at a final concentration of $20 \mu \mathrm{M}$, and then imaged immediately. Images were obtained using a JEOL 1200 EX (JEOL Ltd., Tokyo, Japan) transmission electron microscope immediately after dissolution of peptide lyophilizates. Scale bar $=$ $0.15 \mu \mathrm{m}$. Arrows and circles indicate specific structures (see main text for explanations). The micrographs shown in each panel are representative of the morphologies observed during scanning of the entire grid surface. 


\section{Supporting Information}
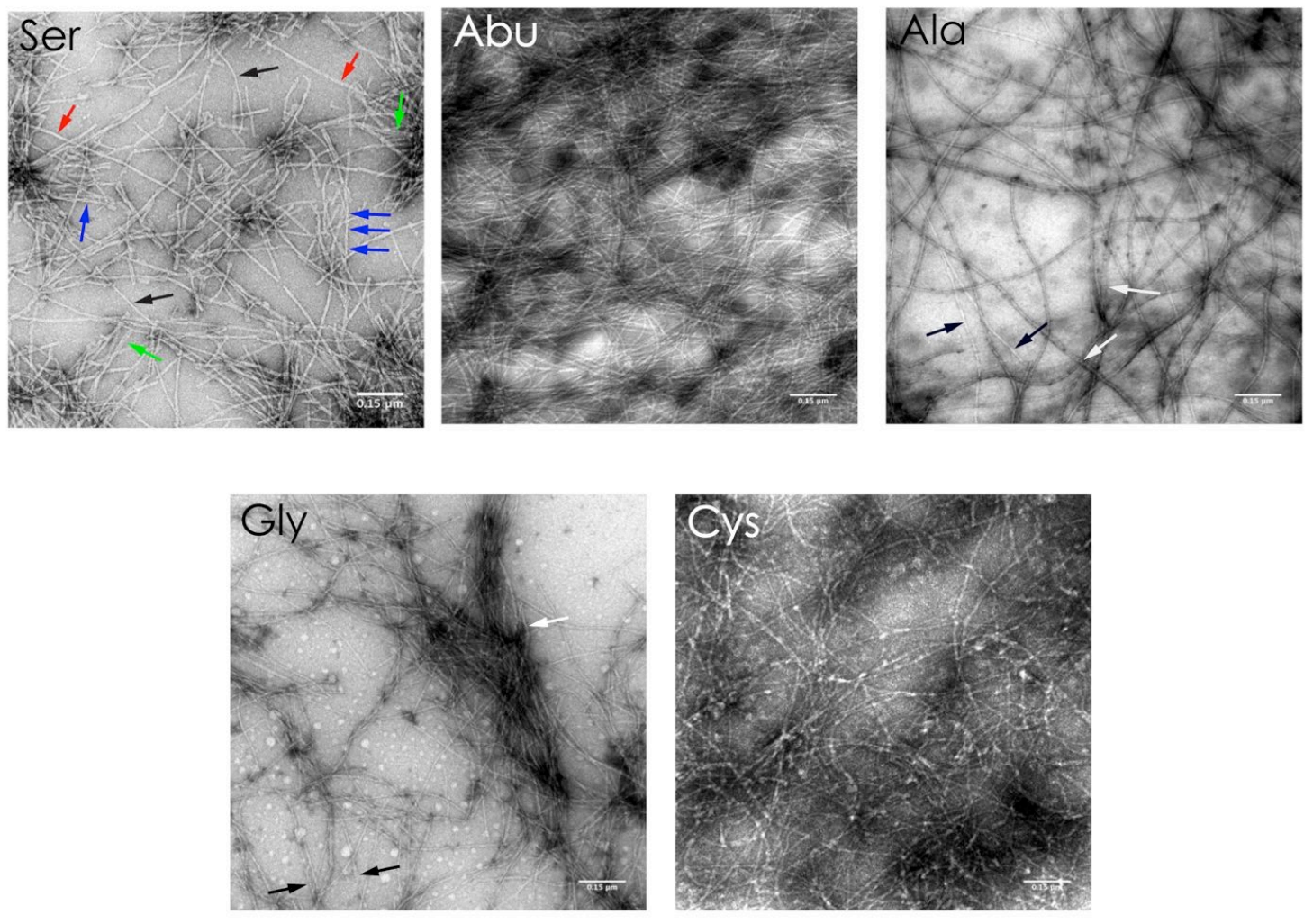

Figure S3B. Electron microscopy of peptide assemblies after $14 \mathrm{~d}$ of incubation. Peptides

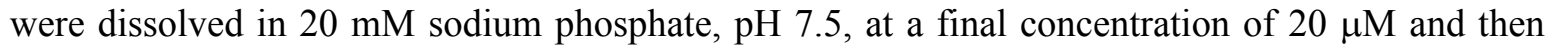
incubated at $37^{\circ} \mathrm{C}$. Images were obtained using a JEOL 1200 EX (JEOL Ltd., Tokyo, Japan) transmission electron microscope $14 \mathrm{~d}$ after dissolution of peptide lyophilizates. Scale bar $=0.15$ $\mu \mathrm{m}$. Arrows indicate specific structures (see main text for explanations). The micrographs shown in each panel are representative of the morphologies observed during scanning of the entire grid surface. 


\section{Supporting Information}

\begin{tabular}{|c|l|l|l|l|l|}
\hline Band $^{\mathbf{a}}$ & \multicolumn{1}{c|}{ Ala } & \multicolumn{1}{c|}{ Abu } & \multicolumn{1}{c|}{ Gly } & \multicolumn{1}{c|}{ Cys } & \multicolumn{1}{c|}{ Ser } \\
\hline $\mathbf{1}$ & $21.5(0.6)$ & $19.6(0.09)^{*}$ & $18.2(0.2)^{* *}$ & $21.5(0.33)$ & $21.7(0.35)$ \\
\hline $\mathbf{2}$ & $19.7(0.06)^{* *}$ & $23.3(0.16)^{* *}$ & $22.2(1.4)$ & $20.7(0.66)$ & $21.4(0.06)$ \\
\hline $\mathbf{3}$ & $14.8(0.32)^{*}$ & $16.1(0.19)^{* *}$ & $15.4(0.15)^{* *}$ & $13.5(0.2)^{*}$ & $12.2(0.09)$ \\
\hline $\mathbf{4}$ & $14.6(0.16)^{* *}$ & $13.3(0.06)^{* *}$ & $14.5(0.03)^{* *}$ & $14.7(0.23)^{* *}$ & $12.0(0)$ \\
\hline $\mathbf{5}$ & $14.2(0.15)^{*}$ & $13.5(0.11)^{*}$ & $13.4(0.1)^{* *}$ & $13.3(0.15)$ & $12.7(0.09)$ \\
\hline $\mathbf{6}$ & $11.6(0.2)$ & $10.3(0.05)$ & $11.4(0.16)$ & $11.2(0.27)$ & $11.0(0.63)$ \\
\hline $\mathbf{7}$ & $3.5(0.15)^{* *}$ & $3.9(0.03)^{* *}$ & $4.8(1.6)$ & $5.1(1.5)$ & $7.8(0.12)$ \\
\hline
\end{tabular}

Table S1. Densitometric analysis of oligomer band intensities. Band intensities from silver stained SDS gels of cross-linked peptide preparations were determined using ImageJ (http://imagej.nih.gov/ij). Numbers in the Band column correspond to monomer (1) or to oligomer order (2-7). Numbers under the respective peptide identifiers are averaged (replicates $\geq 3$ ) normalized intensities ( \pm standard errors), where

$$
N_{i}=I_{i} / \sum_{i=1}^{n} I_{i}
$$

and $\boldsymbol{I}_{\boldsymbol{i}}$ is the intensity of each band $\boldsymbol{i}$. ND is "not detected." The statistical significance of the difference between each band intensity of Ser and each respective band intensity of each of the other peptides is represented by the symbols: ${ }^{*} p<0.05, * * p<0.01$. Significance was determined using paired student $t$ tests as implemented in KaleidaGraph (v4.5.2, Synergy Software, Reading, PA 19606). 


\section{Supporting Information}

\begin{tabular}{|c|c|c|c|c|c|c|}
\hline Peptide & \multicolumn{3}{|c|}{ Day 0 } & \multicolumn{3}{|c|}{ Day 14 } \\
\hline Ser & Globules & Short fibrils & Long fibrils & Globules & Short fibrils & Long fibrils \\
\hline Abu & $\begin{array}{c}4.8-23 \\
(18-48)\end{array}$ & $\begin{array}{c}7.1-8.9 \\
(66-130)\end{array}$ & - & - & $\begin{array}{r}5.8-10.6 \\
(17-118)\end{array}$ & $5.8-11.3$ \\
\hline Ala & $\begin{array}{c}4.2-6.6 \\
(80-127)\end{array}$ & $6.5-15.3$ & - & - & $4.5-11.4$ \\
\hline Gly & $\begin{array}{c}28-57.6-48 \\
(67-98)\end{array}$ & $\begin{array}{c}118-20 \\
(60-138)\end{array}$ & - & - & - & $3.8-11$ \\
\hline Cys & $\begin{array}{c}17-25) \\
(48-81)\end{array}$ & - & - & - & - & $3.7-5.5$ \\
\hline
\end{tabular}

Table S2. Dimensions of assemblies observed by EM. Peptides were incubated at $37^{\circ} \mathrm{C}$ with shaking. Aliquots of assemblies were removed at day 0 and day 14 and then studied by negative stain EM. Numbers indicate diameters (nm) of assemblies. Assembly lengths (nm) are reported within parentheses. Symbol: *, thick fibril; - , not detected. 